This is the author-created draft version of:

The influence of the gas exchange and transpiration of C3 and CAM-facultative species on the green roof's cooling performance

Authors: M. D'Arco, T. Blanusa and M. Speranza

ISHS Acta Horticulturae 1215 pp. 61-66

The original publication is available at DOI 10.17660/ActaHortic.2018.1215.11 


\title{
The influence of the gas exchange and transpiration of C3 and CAM-facultative species on the green roof's cooling performance
}

\author{
M. D’Arco ${ }^{1, a}$, T. Blanusa ${ }^{2,3}$ and M. Speranza ${ }^{1}$ \\ 1Dipartimento di Scienze Agrarie (DipSA), Bologna, Italy; ${ }^{2}$ RHS Wisley, Woking, United Kingdom; ${ }^{3}$ School of \\ Agriculture, Policy and Development, Reading, United Kingdom.
}

\begin{abstract}
Crassulacean acid metabolism (CAM) allows succulent species to survive under drought by reducing the daytime water loss and gas exchange. We compared gas exchange of two CAM-facultative species (Sedum lydium Boiss. and Sedum kamtschaticum Fisch.) and three C3 species of semi-xeric habitats (Lotus corniculatus L., Bromus erectus Huds. and Salvia officinalis L.) during a gradual reduction of substrate moisture content (SMC). The aim was to describe how the C3 and the CAMfacultative species modify their gas exchange rates when the substrate dries out gradually, as well as to identify the critical value of SMC that stops the transpiration. Additionally, we tested the cooling capacity of specie in a week-long glasshouse experiment, in vegetated containers with commercial green roof substrate. The net $\mathrm{CO}_{2}$ assimilation (A) rates of $\mathrm{C} 3$ species were significantly higher than those of CAMfacultative species. When SMC fell below $12 \% \mathrm{v} / \mathrm{v}$, Sedum species showed a rapid decline of A due to the likely switch from C3 to CAM metabolism. However, the high rates of gas exchange of C3 species caused a rapid decline of RWC over the course of the experiment and death of some leaves. The lower substrate temperatures under C3 plants confirmed the positive effect of high gas exchange rates and transpiration on the cooling capacity. We conclude that the use of $\mathrm{C} 3$ plants, with sustainable irrigation (to maintain at least, on average, $10 \% \mathrm{v} / \mathrm{v}$ of SMC), has a potential to provide greater cooling to a green roof than the use of Sedum species.
\end{abstract}

Keywords: green infrastructures (GI), cooling effect, wild plants, net assimilation rate (A)

\section{INTRODUCTION}

Sedum species (family Crassulaceae) are a popular plant choice on green roofs thanks to their ability to survive drought by activating the facultative crassulacean acid metabolism (CAM) (Herrera, 2009). Facultative CAM plants reduce daytime gas exchange and transpiration under drought conditions, which aids survival but decreases the transpirational cooling performance of green roofs. Many C3 wild plant species in the Mediterranean area, however, are adapted to grow under harsh conditions without the use of CAM metabolism and could thus represent an important resource for increasing the pool of species for green roofs (Caneva et al., 2015; Vestrella et al., 2015). In this paper we compared the net $\mathrm{CO}_{2}$ assimilation (A) rates of two Sedum facultative CAM species (Sedum lydium Boiss. and Sedum kamtschaticum Fisch.) and three C3 species (Bromus erectus Huds., Lotus corniculatus L., Salvia officinalis L.) during a gradual reduction of moisture content in the growing medium. The aim was to observe if the evapo-transpiration (estimated via net assimilation rate) of C3 species is higher than Sedum. Also to establish a substrate moisture level at which Sedum species change their metabolism from C3 to CAM and, consequently, deduce if C3 species could have better cooling capacity than facultative CAM species under both well-watered and drought conditions. 


\section{MATERIALS AND METHODS}

This study was conducted in the ventilated glasshouses within the School of Agriculture, Policy and Development, University of Reading (UK). Twelve boxes ((l) $43.5 \mathrm{~cm}$ $\times(w) 35.0 \mathrm{~cm} \times$ (d) $9.0 \mathrm{~cm}$ ) were prepared, two for each plant species tested and two with bare substrate (control). All boxes were filled with the same weight of green roof substrate (Shire Extensive Substrate, Shire Minerals, UK) and they were planted to achieve full ground coverage. All boxes were well watered until the field capacity (on average $29 \% \mathrm{v} / \mathrm{v}$ ) $24 \mathrm{~h}$ before the start and then, left to dry until reaching critical values of substrate moisture content (under $5 \% \mathrm{v} / \mathrm{v}$ ). During the experimental period (from June 14 to 21), the mean daytime air temperature ranged $23-30^{\circ} \mathrm{C}$.

Net $\mathrm{CO}_{2}$ assimilation rate (A) was measured daily, between $12 \mathrm{pm}$ and $4 \mathrm{pm}$, using portable infrared gas analyzer (LCi Portable Photosynthesis System, ADC BioScientific Ltd., Hoddesdon, UK), on five leaves or springs per box. Except for S. officinalis, it was impossible to fit individual leaves into the analyser's cuvette, so springs containing several leaves (and covering the entire cuvette) were chosen and repeatedly measured. At the end of the experiment, the leaf areas of each spring were determined using a leaf area meter (WinDias 3, Leaf Image Analysis System, Delta-T Devices Ltd., Cambridge, UK) and assimilation outputs adjusted where necessary, to relate to the area of the cuvette $\left(6.25 \mathrm{~cm}^{2}\right)$. The substrate moisture content (SMC) of each box was monitored daily using SM200 probe (Delta-T Devices Ltd., Cambridge, UK). The substrate temperatures were monitored continuously using two thermistors (type $\mathrm{T}$ fine PTFE insulated twin twisted wires) positioned at 1-2 cm depth in the middle of each box and connected to the DL2e data logger (Delta-T Devices Ltd., Cambridge, UK); data were collected every 1 min and averaged over 30 min. The leaf temperatures were measured daily (concurrently with A measurements) for each box using Infrared Thermal Camera NEC TH7700 (NEC San-ei Instruments Ltd., Japan). Leaf area index (LAI) of each species was determined at the end of the experiment by dividing the plants' leaf area with the $20 \times 20 \mathrm{~cm}$ area of the substrate, from which plants were collected. The relative water content (RWC) was determined according to Živčák (2008) at the end of experiment. Data were statistically analysed using GenStat (15 ${ }^{\text {th }}$ Edition, Lawes Agricultural Trust, Rothamsted Experimental Station, UK) to compare the species for their A and final RWC.

\section{RESULTS}

\section{Net assimilation rate}

The C3 species showed higher assimilation rates than the two Sedum species; all species showed a rapid decline of net A (Table 1) from day 5, as SMC ranged between $13 \%$ $\mathrm{v} / \mathrm{v}(S$. officinalis) and $9 \% \mathrm{v} / \mathrm{v}$ (B. erectus). The net A rate decreased faster for B. erectus and L. corniculatus than Sedum species and S. officinalis, particularly between days 5 and 6.

\section{Leaf temperatures}

All studied species had leaf temperatures that were $1.6-8.8^{\circ} \mathrm{C}$ lower than surface temperatures of bare substrate (Figure 1A). Between the species, except on day 3 and on day 5 , B. erectus, L. corniculatus and S. officinalis showed lower leaf temperatures than Sedum species for the whole duration of the experiment. On average, the leaf temperatures of $\mathrm{C} 3$ species were $2.06^{\circ} \mathrm{C}$ lower than the leaf temperatures of two Sedum species. Also during the decline of net A (from day 5) due to a decrease of SMC, all C3 species continued to show the coolest leaf temperatures, in particular $S$. officinalis. 
Table 1. Mean net assimilation rate $\left(\mu \mathrm{mol} \mathrm{m} \mathrm{m}^{-2} \mathrm{~s}^{-1}\right)$ and the corresponding substrate moisture content (SMC) value for all studies species over the course of the experiment. Net assimilation data are mean of 10 measurements per species. The percentages of SMC (v/v) are mean of six measurement per treatment.

\begin{tabular}{lcccccccc}
\hline Net assimilation rate & Day 1 & Day 2 & Day 3 & Day 4 & Day 5 & Day 6 & Day 7 & Day 8 \\
and SMC (v/v) & $\mathbf{1 4 / 6}$ & $\mathbf{1 5 / 6}$ & $\mathbf{1 6 / 6}$ & $\mathbf{1 7 / 6}$ & $\mathbf{1 8 / 6}$ & $\mathbf{1 9 / 6}$ & $\mathbf{2 0 / 6}$ & $\mathbf{2 1 / 6}$ \\
\hline B. erectus & 13.79 & 12.87 & 12.83 & 13.97 & 12.17 & 3.85 & 1.00 & - \\
SMC & $29 \%$ & $20 \%$ & $17 \%$ & $14 \%$ & $9 \%$ & $4 \%$ & $2 \%$ & \\
L. corniculatus & 22.76 & 19.68 & 22.53 & 24.14 & 23.62 & 11.40 & 9.32 & - \\
SMC & $26 \%$ & $20 \%$ & $16 \%$ & $15 \%$ & $11 \%$ & $5 \%$ & $4 \%$ & \\
S. officinalis & 17.90 & 15.99 & 17.97 & 18.07 & 17.63 & 16.36 & 10.31 & 4.75 \\
SMC & $25 \%$ & $21 \%$ & $18 \%$ & $15 \%$ & $13 \%$ & $10 \%$ & $3 \%$ & $2 \%$ \\
S. lydium & 7.71 & 8.52 & 9.11 & 10.41 & 7.60 & 5.50 & 2.60 & 0.38 \\
SMC & $26 \%$ & $19 \%$ & $17 \%$ & $16 \%$ & $12 \%$ & $10 \%$ & $5 \%$ & $3 \%$ \\
S. kamtschaticum & 7.13 & 5.80 & 6.69 & 7.14 & 5.29 & 2,73 & 0.78 & 0.21 \\
SMC & $28 \%$ & $21 \%$ & $19 \%$ & $15 \%$ & $12 \%$ & $6 \%$ & $4 \%$ & $2 \%$ \\
\hline Net assimilation least & 2.88 & 3.37 & 3.60 & 3.37 & 2.31 & 2.73 & 2.63 & 1.78 \\
significant difference (LSD) & & & & & & & & \\
\hline
\end{tabular}

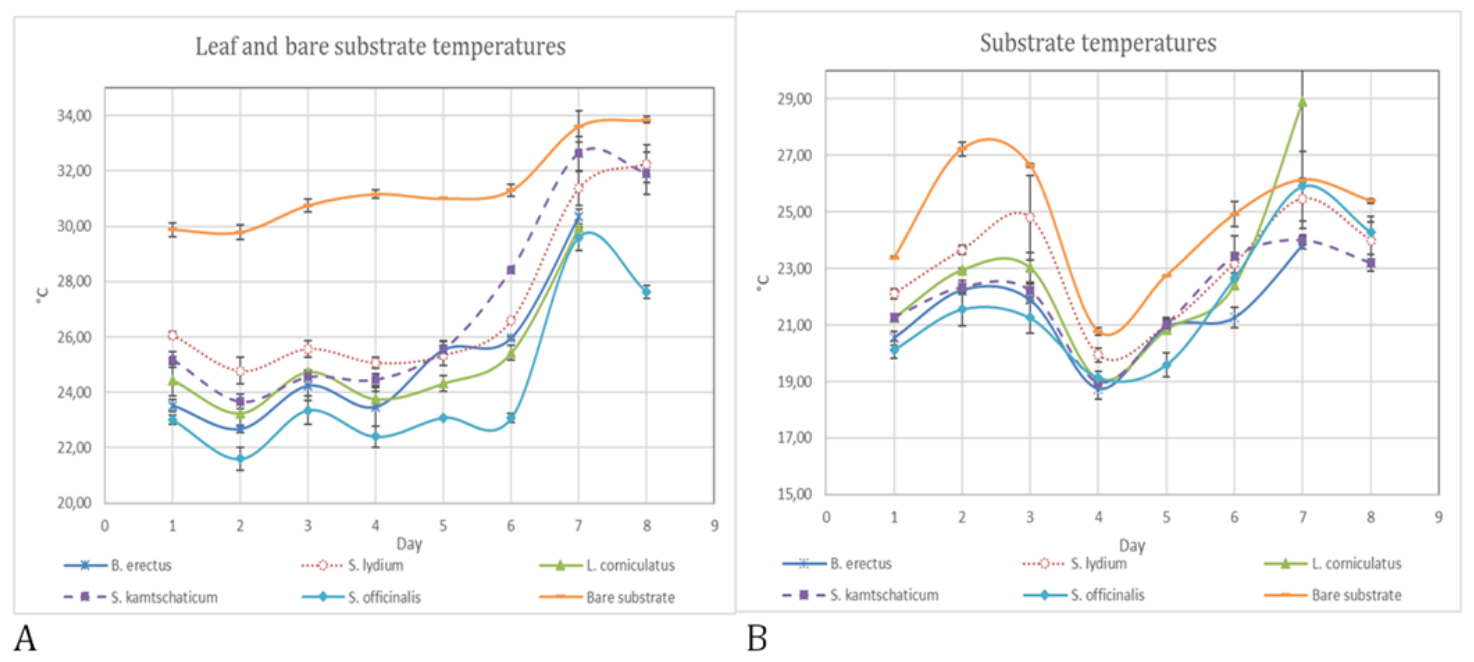

Figure 1. A) Leaf temperatures and bare substrate temperatures measured between $12 \mathrm{pm}$ and $4 \mathrm{pm}$. Data are mean of 6 measurements per species and substrate; B) Mean substrate temperatures at $1 \mathrm{~cm}$ depth for all species and bare substrate. Data are means of two measurements per treatment.

\section{Substrate temperatures}

As we expected, substrate temperatures (Figure 1B) were always cooler than leaf or surface temperatures, but we observed also that the substrate temperatures in all planted boxes with plants were lower than in the boxes without plants. In general, L. corniculatus had hottest substrate temperatures among the C3 species and S. lydium showed the hottest temperatures among all plant species considered. In particular, until the day 4 (under wellwatered conditions), S. officinalis, B. erectus and S. kamtschaticum showed the lowest substrate temperatures (by $3.6^{\circ} \mathrm{C}$ lower than bare substrate on day 3 for example). From day 5 , when SMC decreased under $13 \% \mathrm{v} / \mathrm{v}$, all boxes increased their substrate temperatures, but the C3 species continued to show the coolest substrate temperatures or, in the worst cases, the same substrate temperatures of Sedum species (except for L. corniculatus on day 7). On day 6, for example, the C3 species and Sedum species showed, on average, 
temperatures 2.8 and $1.6^{\circ} \mathrm{C}$, respectively, lower than bare substrate.

On the other hands, Sedum species and S. officinalis, provided a small cooling effect for one more day than L. corniculatus and B. erectus for which the experiment ended one day earlier because of their precarious conditions due to water stress.

\section{Final relative water content (RWC)}

The C3 species, especially L. corniculatus and B. erectus, showed a poor ability to maintain acceptable values of RWC until the end of the experiment; these two species reached critical values of RWC ( 40 and $46 \%$, respectively, data not shown) by day 7 . In fact, the leaves of some individuals of $L$. corniculatus and B. erectus began rolling already from day 6. S. officinalis showed, at the end of the experiment (day 8), the highest RWC values (72\%) among the $\mathrm{C} 3$ species tested. However, also for this species, at the end of the experiment, a few leaves per plant were slightly wilted.

\section{DISCUSSION}

\section{Net assimilation rate, substrate moisture content and final RWC}

C3 species had higher net A (and thus likely, transpiration rates) than Sedum. In some cases, net assimilation values of L. corniculatus exceeded 3-fold those of Sedum (e.g., on day 5 when SMC was already below $12 \% \mathrm{v} / \mathrm{v}$ ). There was a decline of the net assimilation when the substrate moisture reached $12 \% \mathrm{v} / \mathrm{v}$ in Sedum and from 11, 10 and $9 \% \mathrm{v} / \mathrm{v}$ in $L$. corniculatus, $S$. officinalis and B. erectus, respectively. CAM species are known to reduce the net assimilation and transpiration in the periods of water stress (Olivares et al., 1984; Borland and Griffiths, 1990). In addition, the results of our previous study (D'Arco et al., 2016) showed the malate accumulation during the dark period in the $S$. lydium and $S$. kamtschaticum leaves, at around $13-10 \% \mathrm{v} / \mathrm{v}$ of SMC. It is thus likely that the shift we are seeing in Sedum was due to the change from C3 to CAM metabolism. The final RWC values showed that the A decline in C3 species is followed by a rapid and significant drop in RWC. Sedum species demonstrated to have the capacity to maintain a high quantity of water in the leaves also under severe drought $(>87 \%$ of RWC when the SMC values dropped below $6 \%$ $\mathrm{v} / \mathrm{v}$ ). B. erectus and L. corniculatus plants, which transpired more than Sedum species, reached at the end of experiment, values of SMC considered critical (Babu et al., 1999) and started to show the visible signs of water stress (rolling leaves and drying). S. officinalis is an exception; it transpired more than Sedum, but at the end of the experiment, the average RWC values were still higher than the critical limit and no part of plant material was lost.

We suggest that the use of C3 species (in particular $S$. officinalis) could increase significantly the cooling effect of the green roof through the transpiration at least until about $9 \% \mathrm{v} / \mathrm{v}$ of SMC.

\section{Leaf and substrate temperatures}

Active gas exchange $\left(\mathrm{CO}_{2}\right.$ and water vapour) has an important role in the cooling effect; $B$. erectus and S. officinalis showed the lowest substrate and leaf temperatures and the highest A values until day 6 when the SMC dropped to $4 \% \mathrm{v} / \mathrm{v}$ and $10 \% \mathrm{v} / \mathrm{v}$ for these species, respectively. Other factors, including light leaf colour and presence of leaf hairs may also explain Salvia's advantage (Vaz Monteiro et al., 2016). Despite high A, L. corniculatus showed, almost for the whole duration of the experiment, higher substrate temperatures than S. kamtschaticum. This may be explained by the lower LAI of L. corniculatus compared to $S$. kamtchaticum (almost four-fold). S. kamtschaticum could thus provide a positive contribution to the cooling effect by the shading effect of their leaves. Similarly, despite of lower gas exchange of $B$. erectus than $L$. corniculatus, the substrate of B. erectus was cooler and the LAI value was higher than $L$. corniculatus. The contribution of $B$. erectus to the cooling effect was likely the sum of a good transpiration activity, but also of shading. Otherwise, $S$. officinalis showed a lower LAI value (4.45) than B. erectus and $S$. kamtschaticum, but the substrate temperatures of boxes with $S$. officinalis were the coolest thanks to its high gas exchange activity. 


\section{CONCLUSIONS}

This study demonstrates that all C3 species tested showed greater gas exchange activity than $S$. lydium and $S$. kamtschaticum under well-watered conditions but, also, under drought (from about $10 \%$ v/v of SMC), when Sedum facultative CAM species begin to change their metabolism from C3 to CAM. The higher gas exchange capacity of C3 species reduces leaf temperatures and consequently increases the cooling effect of green roofs, particularly during the hot and dry weather. However, this study, also revealed that high LAI and ground coverage are required in addition to high transpiration activity, to maximise the green roof cooling effect.

\section{Literature cited}

Babu, R.C., Pathan, M.S., Blum, A., and Nguyen, H.T. (1999). Comparison of measurement methods of osmotic adjustment in rice cultivars. Crop Sci. 39 (1), 150-158 https://doi.org/10.2135/cropsci1999.0011183X003900 010024x.

Borland, A., and Griffiths, H. (1990). The regulation of CAM and respiratory recycling by water supply and light regime in the C3-CAM intermediate Sedum telephium. Funct. Ecol. 4 (1), 33-39 https://doi.org/10.2307/ 2389649.

Caneva, G., Kumbaric, A., Savo, V., and Casalini, R. (2015). Ecological approach in selecting extensive green roof plants: A data-set of Mediterranean plants. Plant Biosyst. 149 (2), 374-383 https://doi.org/10.1080/11263504. 2013.819819.

D'Arco, M., Ferroni, L., and Speranza, M. (2016). How important is the choice of plant species for the green roof's cooling effect? Comparison of the behavior of two cam-facultative species and two C3 species under drought condition. Paper presented at: III International Plant Science Conference (IPSC), (Rome, Italy).

Herrera, A. (2009). Crassulacean acid metabolism and fitness under water deficit stress: if not for carbon gain, what is facultative CAM good for? Ann. Bot. 103 (4), 645-653 https://doi.org/10.1093/aob/mcn145. PubMed

Monteiro, M.V., Blanuša, T., Verhoef, A., Hadley, P., and Cameron, R.W.F.. (2016). Relative importance of transpiration rate and leaf morphological traits for the regulation of leaf temperature. Aust. J. Bot. 64 (1), 32-44 https://doi.org/10.1071/BT15198.

Olivares, E., Urich, R., Montes, G., Coronel, I., and Herrera, A. (1984). Occurrence of Crassulacean acid metabolism in Cissus trifoliata L. (Vitaceae). Oecologia 61 (3), 358-362 https://doi.org/10.1007/BF00379635. PubMed

Vestrella, A., Savé, R., and Biel, C. (2015). An experimental study in simulated greenroof in Mediterranean climate. J. Agric. Sci. 7 (4), 95 https://doi.org/10.5539/jas.v7n4p95. 
